\title{
Membrane Transporters and Pharmacological Implications
}

Luca Cucullo ${ }^{* 1,2}$ and Taylor Liles ${ }^{1}$

${ }^{1}$ Department of Pharmaceutical Sciences, 1300 S Coulter St, Amarillo TX 79106-1712, USA

${ }^{2}$ Center for Blood-Brain Barrier Research, Texas Tech University Health Sciences Center, Amarillo, TX 79106, USA

*Corresponding author: Luca Cucullo, Department of Pharmaceutical Sciences, Texas Tech University Health Sciences Center, School of Pharmacy, 1300 S. Coulter Street, Amarillo, TX 79106, USA, Tel: 806-414-9237; Fax: 806-356-4034; E-mail: luca.cucullo@ttuhsc.edu

Received date: May 27, 2016; Accepted date: June 03, 2016; Published date: June 08, 2016

Copyright: (c) 2016 Cucullo L, et al. This is an open-access article distributed under the terms of the Creative Commons Attribution License, which permits unrestricted use, distribution, and reproduction in any medium, provided the original author and source are credited.

\section{Introduction}

Membrane transporters serve to move chemicals in and out of the cells according to metabolic needs or the presence of toxic compounds. These processes are mediated by facilitated diffusion or active transport through the lipid bilayer that is the cell membrane. There exist two main categories of membrane transporters, the more passive solute carrier transporters (SLCs) and the ATP binding cassette transporters (ABCs). SLCs allow for passage of ions, sugars, lipids, amino acids and other compounds down a gradient, contributing to a cell's passive permeability for such compounds. ABCs feature a highly conserved nucleotide binding domain (NBD) which contain peptide sequences responsible for ATP hydrolysis such as the Walker A and B motifs. ABCs utilize the energy stored in ATP to transport chemicals against their concentration and/or electrical gradient and consequently alter expected biological conditions. Transporters are now recognized as crucial barriers (e.g., efflux transporters) as well as possible delivery pathways to consider when designing new pharmaceutical agents as many traditional therapeutics are being recognized as transporter substrates [1-3]. Drug resistant tumors and the blood-brain barrier (BBB) for example have been shown to actively express efflux transporters preventing therapeutic agents from reaching clinically relevant intracellular concentrations and/or physiological targets in the brain [4-7].

Consequently, in 2010 the International Transporter Consortium put forth the 'white paper' detailing the structure, location, and known substrates of various pharmacologically relevant transporters. This prompted action from American and European regulatory agencies to release guidelines on transporter-drug interaction studies [3]. PGlycoprotein (MDR1), Breast Cancer Resistance Protein (BCRP), Organic Anion Transporter peptide (OATP), Organic Anion Transporter (OAT), Organic Cation Transporter (OCT), and Multi Drug Resistance Protein (MRP) are mentioned directly in the white paper and have been a focus of the ITC to be included in the in vitro to in vivo extrapolation (IVIVE) which refers to the qualitative or quantitative transposition of in vitro experimental results to predicts a physiological and/or pathological phenomena in vivo. P-glycoproteins (Pgp) and the Cytochrome P450 enzyme CYP3A analogs share a significant number of substrates [8] and are both found in the intestines and liver [9-11]. Together they compose a first pass metabolism barrier for therapeutic agents taken orally $[12,13]$. Because Pgp effluxes compounds from the intestinal wall back into the lumen of the intestines, researchers may mistake increased mean residence time (MRT) for increased absorption when performing PK/PD studies [14]. Some of these CYP analogs such as CYP3A4, CYP2C9, CYP2C19, CYP2A6 and CYP2E1 are also expressed at the BBB endothelial level of the BBB under pathological conditions (e.g., drug resistant epilepsy). In some cases, the expression of a CYP enzyme (e.g., CYP3A CYP2C19 and CYP2C9) is regulated by the activation of the xenobiotic receptor pregnane $\mathrm{X}$ receptor (PXR) which also controls the expression of Pgp and other drug efflux systems $[15,16]$. With regard to the drug efflux transporters at the BBB level, multidrug resistance (MDR) is a major obstacle to treating patients with cancer and is often the result of overexpression of a 170 - to $180-\mathrm{kDa}$ plasma membrane glycoprotein known as P-glycoprotein (Pgp) [17,18] and multidrug resistancerelated proteins (MRP1, $190 \mathrm{kDa}$ ) [19,20]. Human Pgp is encoded by MDR1 and rodent Pgp by Mdrla and Mdr1b [21-24]. Pgp and MRPs belong to the superfamily of ATP-binding cassette transporters. Unlike other selective (classical) transport proteins, MDR proteins recognize a wide range of substrates. This wide substrate specificity explains the cross-resistance to several chemically unrelated compounds, the characteristic feature found in the multi-drug resistance phenotype. In addition to their overlapping substrates specificity, each transporter can handle unique compounds. Pgp-MDR1 is a transporter for large amphipathic compounds either uncharged or slightly charged while the MRP family is mostly transporting hydrophobic anionic conjugates with glucuronide, sulfate or glutathione and also extrudes hydrophobic uncharged drugs [19]. Experiments designed to define the structure of Pgp suggest that there is no simple single drug-binding site or pore in Pgp. Amino acid substitutions in, or near, most of the transmembrane segments affect substrate specificity or transport efficiency. In drug refractory patients a synergistic effect between MDRs and CYP enzymes has been recently observed which antagonizes the passage of drugs targeting the brain (e.g., antiepileptics, tumor suppressants, etc.) through a concerted set of mechanisms [15]. The efflux transporters extrude the drug from the brain across the BBB back into the blood circulation while the CYP enzyme metabolize the drug substrate into (at large) inactive derivate(s), thus rendering the drug bioavailability ineffective from a therapeutic standpoint. Other than MDR, altered activity of efflux transporters have been linked to a number of neurological disorders including Alzheimer's disease [25], Parkinson's diseases [26] and Creutzfeldt-Jakob disease [27].

\section{References}

1. Giacomini KM, Huang SM, Tweedie DJ, Benet LZ, Brouwer KL, et al. (2010) Membrane transporters in drug development. Nat Rev Drug Discov 9: 215-236.

2. Hillgren KM, Keppler D, Zur AA, Giacomini KM, Stieger B, et al. (2013) Emerging transporters of clinical importance: an update from the International Transporter Consortium. Clin Pharmacol Ther 94: 52-63.

3. Maeda K, Sugiyama Y (2013) Transporter biology in drug approval: regulatory aspects. Mol Aspects Med 34: 711-718.

4. Daood M, Tsai C, Ahdab-Barmada M, Watchko JF (2008) ABC transporter (P-gp/ABCB, MRP1/ABCC, BCRP/ABCG2) expression in the developing human CNS. Neuropediatrics 39: 211-218. 
Citation: Cucullo L, Liles T (2016) Membrane Transporters and Pharmacological Implications. J Pharmacovigil 4: e155. doi:

Page 2 of 2

5. Doyle LA, Yang W, Abruzzo LV, Krogmann T, Gao Y, et al. (1998) A multidrug resistance transporter from human MCF-7 breast cancer cells. Proc Natl Acad Sci U S A 95: 15665-15670.

6. Marchi N, Granata T, Alexopoulos A, Janigro D (2012) The blood-brain barrier hypothesis in drug resistant epilepsy. Brain 135: e211.

7. Qosa H, Miller DS, Pasinelli P, Trotti D (2015) Regulation of ABC efflux transporters at blood-brain barrier in health and neurological disorders. Brain Res 1628: 298-316.

8. Benet LZ (2009) The drug transporter-metabolism alliance: uncovering and defining the interplay. Mol Pharm 6: 1631-1643.

9. Fakhoury M, Litalien C, Medard Y, Cavé H, Ezzahir N, et al. (2005) Localization and mRNA expression of CYP3A and P-glycoprotein in human duodenum as a function of age. Drug Metab Dispos 33: 1603-1607.

10. Hebert MF (1997) Contributions of hepatic and intestinal metabolism and P-glycoprotein to cyclosporine and tacrolimus oral drug delivery. Adv Drug Deliv Rev 27: 201-214.

11. Kusuhara H, Sugiyama Y (2009) In vitro-in vivo extrapolation of transporter-mediated clearance in the liver and kidney. Drug Metab Pharmacokinet 24: 37-52.

12. Hendrikx JJ, Lagas JS, Rosing H, Schellens JH, Beijnen JH, et al. (2013) Pglycoprotein and cytochrome $\mathrm{P} 4503 \mathrm{~A}$ act together in restricting the oral bioavailability of paclitaxel. Int J Cancer 132: 2439-2447.

13. van Waterschoot RA, Schinkel AH (2011) A critical analysis of the interplay between cytochrome P450 3A and P-glycoprotein: recent insights from knockout and transgenic mice. Pharmacol Rev 63: 390-410.

14. Zamek-Gliszczynski MJ, Lee CA, Poirier A, Bentz J, Chu X, et al. (2013) ITC recommendations for transporter kinetic parameter estimation and translational modeling of transport-mediated PK and DDIs in humans. Clin Pharmacol Ther 94: 64-79.

15. Ghosh C, Puvenna V, Gonzalez-Martinez J, Janigro D, Marchi N (2011) Blood-brain barrier P450 enzymes and multidrug transporters in drug resistance: a synergistic role in neurological diseases. Curr Drug Metab 12: 742-749.

16. Moon JY, Gwak HS (2015) Role of the nuclear pregnane X receptor in drug metabolism and the clinical response. Receptors \& Clinical Investigation 2.
17. Naito M, Tsuruo T (1998) Therapeutic approach to drug resistant tumors. Ther Drug Monit 20: 577-580.

18. Tsuruo T, Naito M, Tomida A, Fujita N, Mashima T, et al. (2003) Molecular targeting therapy of cancer: drug resistance, apoptosis and survival signal. Cancer Sci 94: 15-21.

19. Ishikawa T, Kuo MT, Furuta K, Suzuki M (2000) The human multidrug resistance-associated protein (MRP) gene family: from biological function to drug molecular design. Clin Chem Lab Med 38: 893-897.

20. Spiegl-Kreinecker S, Buchroithner J, Elbling L, Steiner E, Wurm G, et al. (2002) Expression and functional activity of the ABC-transporter proteins P-glycoprotein and multidrug-resistance protein 1 in human brain tumor cells and astrocytes. J Neurooncol 57: 27-36.

21. Bush JA, Li G (2002) Regulation of the Mdr1 isoforms in a p53-deficient mouse model. Carcinogenesis 23: 1603-1607.

22. Lazarowski A, Sevlever G, Taratuto A, Massaro M, Rabinowicz A (1999) Tuberous sclerosis associated with MDR1 gene expression and drugresistant epilepsy. Pediatr Neurol 21: 731-734.

23. Schinkel AH, Wagenaar E, van Deemter L, Mol CA, Borst P (1995) Absence of the mdrla P-Glycoprotein in mice affects tissue distribution and pharmacokinetics of dexamethasone, digoxin, and cyclosporin A. J Clin Invest 96: 1698-1705.

24. Tishler DM, Weinberg KI, Hinton DR, Barbaro N, Annett GM, et al. (1995) MDR1 gene expression in brain of patients with medically intractable epilepsy. Epilepsia 36: 1-6.

25. Vogelgesang S, Cascorbi I, Schroeder E, Pahnke J, Kroemer HK, et al. (2002) Deposition of Alzheimer's beta-amyloid is inversely correlated with P-glycoprotein expression in the brains of elderly non-demented humans. Pharmacogenetics 12: 535-541.

26. Vautier S, Fernandez C (2009) ABCB1: the role in Parkinson's disease and pharmacokinetics of antiparkinsonian drugs. Expert Opin Drug Metab Toxicol 5: 1349-1358.

27. Vogelgesang S, Glatzel M, Walker LC, Kroemer HK, Aguzzi A, et al. (2006) Cerebrovascular P-glycoprotein expression is decreased in CreutzfeldtJakob disease. Acta Neuropathol 111: 436-443. 